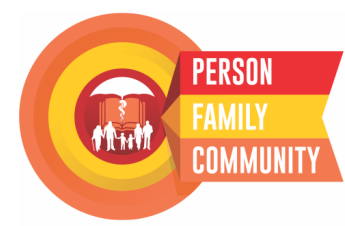

Journal Homepage:

https://jurnal.ugm.ac.id/rpcpe
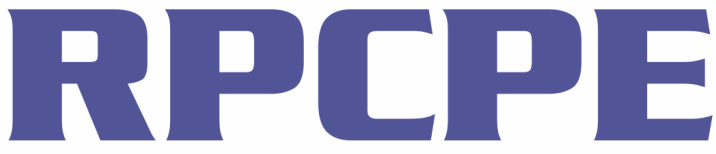

ISSN 2613-943X (print) ISSN 2620-5572 (online)

Review of Primary Care Practice and Education (Kajian Praktik dan Pendidikan Layanan Primer)

\title{
Scientific Prediction of the Covid-19 Pandemic and What Should Society Do?
}

\author{
Iche Andriyani Liberty ${ }^{1}$, Mariatul Fadilah ${ }^{2}$, Hari Kusnanto Josef ${ }^{3}$
}

\begin{abstract}
${ }^{1}$ Department of Public Health and Community Medicine; Faculty of Medicine; Sriwijaya University; Indonesia
${ }^{2}$ Department of Public Health and Community Medicine; Faculty of Medicine; Sriwijaya University; Indonesia

${ }^{3}$ Department of Family Medicine and Community Medicine; Faculty of Medicine, Public Health, and Nursing; Universitas Gadjah Mada; Indonesia
\end{abstract}

Presented at the webinar organized by the collaboration between the Indonesian Family Medicine College, the Indonesian Family Doctors Association, the Indonesian Society of Teachers in Family Medicine, the Review-Journal on Primary Care Practice and Education, and the Center for Policy Management, the Faculty of Medicine, Gadjah Mada University on April 8, 2020.

Corresponding Author:

Iche Andriyani Liberty: Department of Public Health and Community Medicine; Faculty of Medicine; Sriwijaya University; Indonesia E-mail: iche.aliberty@gmail.com

To cite this article:

Liberty IA, Fadilah M, Josef HK. Scientific Prediction of the Covid-19 Pandemic and What Should Society Do?. Rev Prim Care Prac and Educ. 2020; 3(3): 22-26.

What is the scientific prediction for the Covid-19 pandemic? Currently, as of April 8, the world's confirmed cases have over 1.2 million, the death of more than 72 thousand. For Indonesia, today 2,738 confirmed cases, 221 deaths, and those who recovered 204.1-3. The update on April 8 today, WHO itself estimates that the Covid-19 Contagion Rate is 1.4 to $2.5^{1}$. This will form the basis of predictive modeling. Several studies conducted show that currently the basic reproduction number or R0 of Covid-19 is higher than $\mathrm{SARS}^{2}$. Initially in the range of $2-3$ or an average of 2.5 , currently R0 is $1.4-6.9$. This is what will form the basis of modeling. R0 or the basic reproduction number shows how many people a person can become infected with. If the R0 is more than 1 , we are in an epidemic status as it is today, R0 = 1 endemic, and our R0 is less than 1 we have eradicated. R0 itself consists of three components, namely $\mathrm{p}$ : transmission, $\mathrm{c}$ : number of contact, and D which is the duration of the infection itself. These calculations are the main points in modeling.
Some literature shows that the average contact rate when the study was conducted in Europe in 8 countries, the average was 14 . The highest was in Italy, namely 19.77 and in the Netherlands it was around 14.4. This is the prediction scenario for Indonesia. If our contact rate is 20 , then our R0 is 7, assuming the duration of infection is 14 days and transmission is 2.5 . If our contact rate is 14 , then our R 0 is 4.9. When our contact rate is 10 , then our $\mathrm{R} 0$ is 3.5 , and if our contact rate is 4 , then our R0 is 1.4 .

Epidemic modeling uses Susceptible Infected Recovered which consists of three components, namely S: those who are vulnerable but have not been infected with the disease. Yang I (Infected): the number of infected individuals, if here consists of people under monitoring and people without symptoms, and $\mathrm{R}$, namely individuals who have recovered from the disease. With the assumption, this modeling that has been carried out to date is still ignoring whether there will be re-infection.

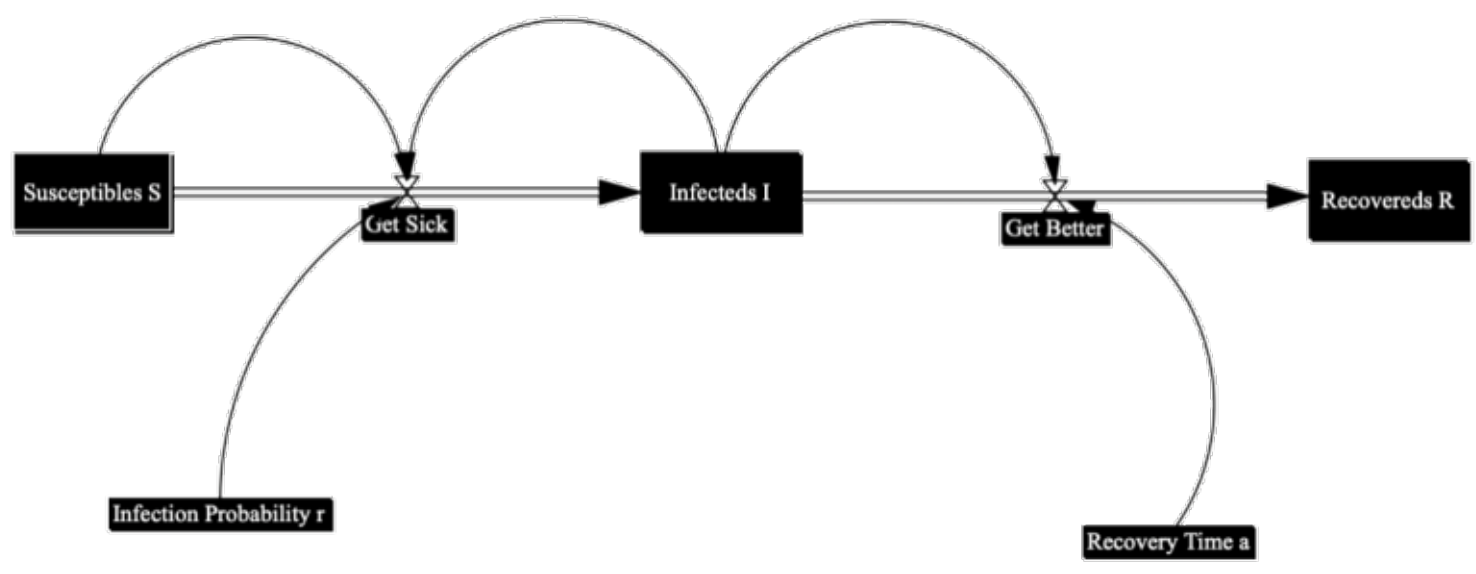


Three "compartments" which can be varied as a function of time $(\mathrm{t})$ :

- $\mathrm{S}(\mathrm{t})$ : those who are susceptible but not infected with the disease;

- I (t): number of infected individuals; ODP and OTG

- $\mathrm{R}(\mathrm{t})$ : individuals who have recovered from the disease.
When the contact rate 14 scenario is used, the number of infections on May 11 will be 20 million. When we use the contact rate scenario 10, it drops again on 11 May 2020 to 1 million infected, and when we use the scenario contact rate $=4$, on 11 May 2020 there are 5,792 infected.

\section{SKENARIO KONTAK SOSIAL $=14$ TANPA INTERVENSI}

Transmisi: 2.5 Periode infeksi: 14 Total Populasi: 268 juta

\section{Ro $=4.9$}

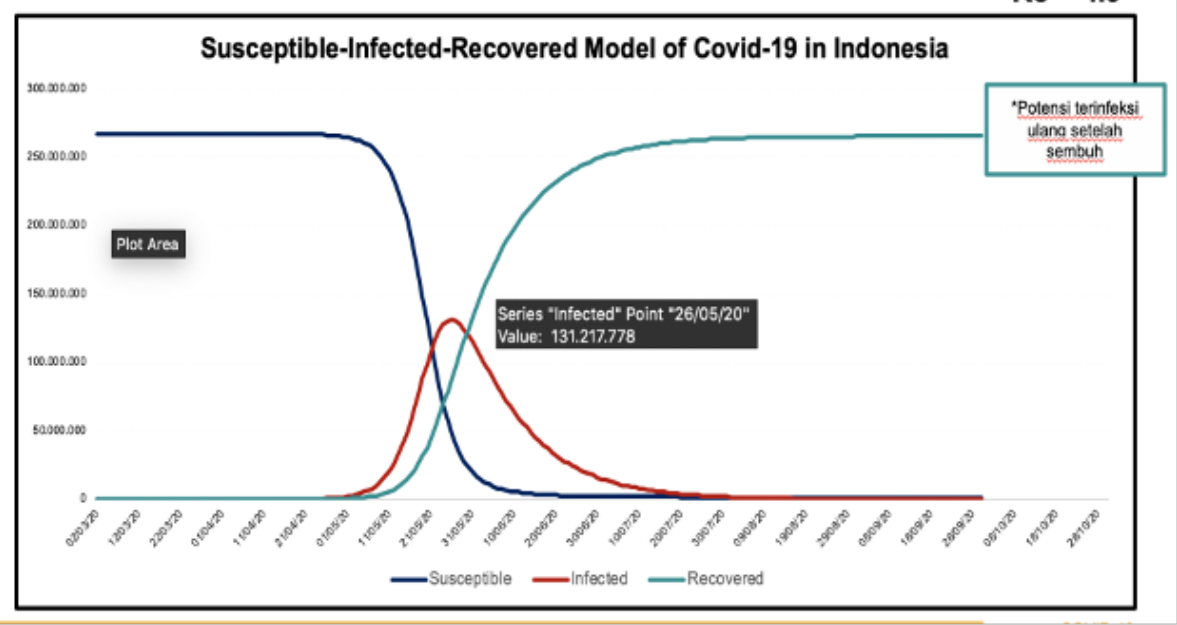

SKENARIO KONTAK SOSIAL = 10 TANPA INTERVENSI

Transmisi: 2.5 Periode infeksi: 14 Total Populasi: 268 juta Ro $=3.5$

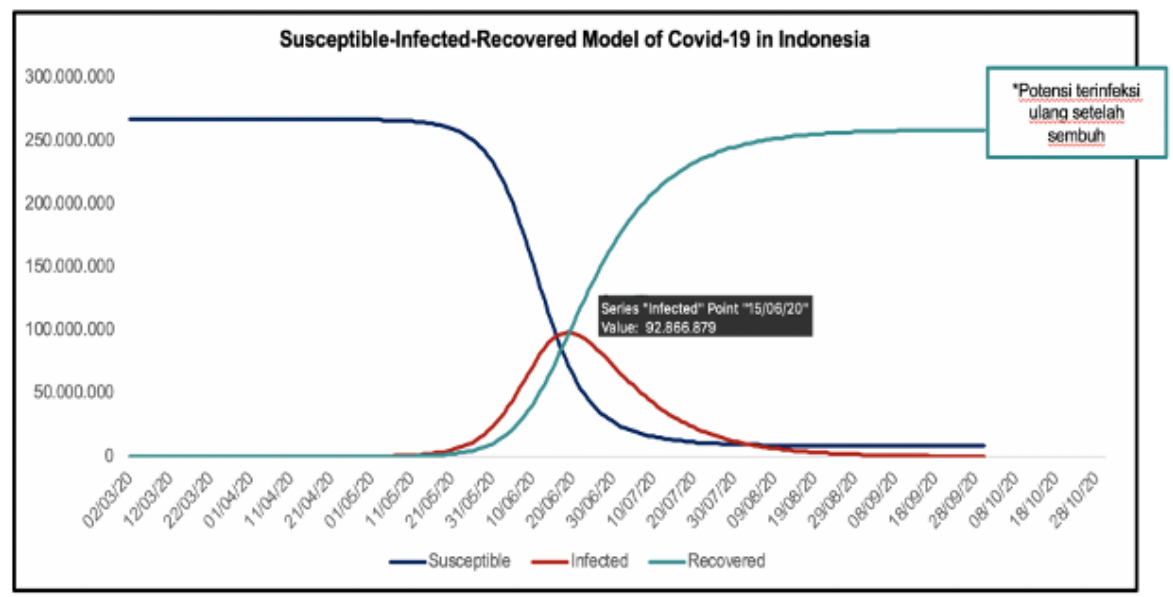

The message from the model about cases of infection is that cases will decrease as the contact rate decreases because of the component of R0. With the assumption that the average number of household members in Indonesia according to BPS is 3.9 or 4, that way, staying at home is the best option to accelerate breaking the chain of case transmission.

Next, how do we derive this case or how to flatten this curve with social distancing? Because until now the non-pharmacological intervention that has been widely recommended from various studies is social distancing. 1 week of social distancing can reduce cases by $66 \%, 2$ weeks can reduce cases by $86 \%$, and 3 weeks can reduce cases by $95 \%$.

If there is social distancing with Law Inforcement or with law enforcement. This is the prediction when there is no intervention, the Infected point when there is no intervention is 131 million more on May 26, 2020, but if social distancing is applied with Law Inforcement as of April 10, 2020, 1 week of social distancing will drop to 44 million. When social distancing is 2 weeks, it goes down again, and when social distancing is applied for 3 weeks, there will be 6 million cases of infection. This is the setting for our contact rate of 14 , because we take an average contact rate of 14 .

What will happen if Law Inforcement on social distancing is implemented after the peak or May 26, of course, many will be infected. That is, when we should enforce Law Inforcement for social distancing, the sooner the better.

It can be concluded that predictions with various scenarios like this give a message that this curve flattening can be 


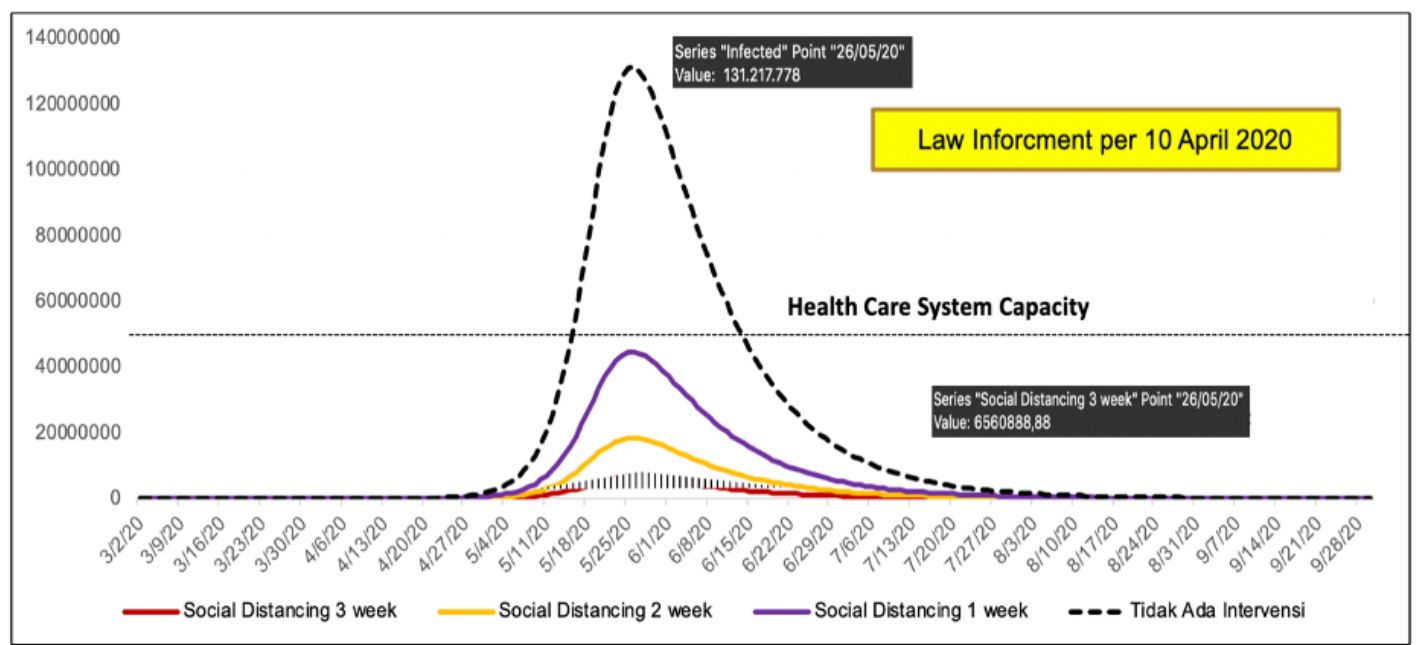

done, by intervening by reducing contact rates, reducing social contacts, of course by social distancing and physical distancing which if applied for 1 week, 2 weeks, 3 weeks have differences in effectiveness ${ }^{3,4}$.

\section{Family, Community and Public Health Medicine Perspective}

This pandemic epidemic made all humans aware that all humans need each other and must be together. Peers who are in primary care are often colleagues in the local area, the task force, and various mass media reminded us that there is something that we all do not just stand by and rely on colleagues who only exist in primary care. Pity those who have tried to do whatever it takes to fight the pandemic that never ends, those who have had direct contact with patients who are positive for Covid-19. Although it can be assumed that PPE and all the equipment they need are complete and very adequate, but colleagues who are in service secondary facing patient.

The Regulation of the Minister of Health of 2020 which was announced yesterday, Number 9 concerning Guidelines for Large-Scale Social Restrictions. There are still a lot of people who do not heed the government's recommendations, even if without doing Law Inforcement and evaluating all policies, it is not impossible that the number of Covid-19 incidents will continue to increase.

Therefore, Ladies and Gentlemen, in this webinar forum, the Faculty of Medicine UNSRI is thinking about what to do? Not only screaming complaining through the mass media, currently in Palembang City, there are several areas that are already in the red zone. In South Sumatra there is an area with very high transmission and is located in the heart of South Sumatra Province. Very difficult It is very difficult to do anything without the policies and participation of local and central government.

Policies for large-scale social restrictions can only be provided by the central government, which means that all policies taken are very dependent on the central government. Therefore, we predict that on May 26 there will be around 160 million people infected in Indonesia. This is a very strong warning that we cannot underestimate Covid-19, because there are many victims, possibly millions. But this is all just a prediction, but from the prediction model the message is very clear that don't let the vulnerable get infected just because they can't find out who has been declared positive for Covid-19. Because it takes a massive and comprehensive test as much as possible. the infected can isolate and not pass it on to other people.

We all convey to the Government, not only by speaking, but also with attitudes. There are many things that doctors who are in primary care can do to stop the chain of transmission of Covid-19 with the community. Education to the community is very important, people only know that doctors only treat. Doctors are not only medicinal, promotive and preventive are also the duties of all of us, therefore education to the public is very important. Support from the government is also very important to carry out this mission, therefore, through this webminar, colleagues can convey any shortcomings that must be corrected immediately.

So people who are asymptomatic but infectious are what we fear so much. "Does this mean a virus like this can exist again? So, can this atmosphere be repeated? So what should the community do ". That is, there will likely be mutations. If that happens, there really is no other way except social distancing, physical distancing, maybe even a lockdown. Because it is not impossible that those who have recovered will be infected again, there have been several journals that have examined the possibility of this reinfection. Therefore, we must inform the entire community that the chain of transmission of Covid-19 will not be able to stop if there is no participation of all communities at the same time.

Personal protective equipment is also a very important role in stopping this chain of transmission, many of the doctor's colleagues only use improvised PPE, only wearing raincoats. Inadequate PPE like this will only cause new problems, many of the medical personnel complain of shortness of breath, diarrhea, skin diseases such as urticaria, etc. due to PPE that is not up to standard like this. Therefore, the participation of the government is very important to prepare PPE that is more comfortable and according to standards for medical personnel so that no more personnel are infected and infected with Covid-19. 
Regarding online health services that are being heralded right now. It is also very important and is a very appropriate solution to prevent contact between patients and medical personnel. Medical personnel can also recommend to patients if it is not in an emergency they can do online consultation. Then what about the patients who need to take routine drugs that require a prescription from the hospital. This can also be done online, in collaboration between hospitals and pharmacies, for example, patients can register all their administration online, then the hospital can provide a letter to the pharmacy to provide routine medicines for the patient. This can reduce human contact, which is likely to continue to increase the Covid-19 transmission line.

It is very interesting, a lot of knowledge and inspiration can be obtained for primary care activists, especially in rural and remote areas of Indonesia. And indeed, from a health perspective, we are currently experiencing an information crisis. So it's not only the head of the Indonesian Covid handling group who has a big influence on the community. But religious figures, influencers, and so on, they have a very big influence on the information circulating among us. So finally we as primary service activists feel that the most important task at this time is to provide correct information about Covid-19 itself, to provide information on how to prevent the most people can do, even the lowest education. That is what we hold today. So that we certainly don't want to be hands off, do not want to stop practicing, do not want to stay away from society, but the more our function is here, the clearer it is that the preventive promotion must be carried out by people who work in primary services. Now this is our strength because the public also has access to the right information. Many people have the media to get information, but they are unable to filter out true and false information. So, this is our concentration in this primary service, to what extent we can be the right information providers for the community. Now this is our strength because the public also has access to the right information. Many people have the media to get information, but they are unable to filter out true and false information. So, this is our concentration in this primary service, to what extent can we be the right information providers for the community. Now this is our strength because the public also has access to the right information. Many people have the media to get information, but they are unable to filter out true and false information. So, this is our concentration in this primary service, to what extent can we be the right information providers for the community.

Then, indeed our problem right now is that the government has not been able to carry out a lockdown and is currently still in the stages of implementing the PSBB. The current PSBB has been implemented, but its impact has not been that massive. Well, this may be our concern in the region. So indeed we all have to provide the time, provide energy, thoughts, how to combine this information into correct and appropriate information for the community. So that they do not experience an information crisis and that is very dangerous for today's society.

To be honest, there is one thing that makes us all upset right now, which is about returning to our hometown.
While those who returned were those from the red zone, almost everything was like that. I agree that in general, when children who return to their hometowns come to their parents' houses, not all of them are sincere if their children are asked to first self-quarantine for 14 days. Maybe this is what we should tell them. Get rid of the miss fast, but after that we're late, it's no use. Therefore, we recommend that in areas that have hajj dormitories, for example, they can be used as quarantine places, but this is really done. It is time now with my friends who returned home, especially younger students who returned home,

"Is the collaboration in providing online doctor services such as Halodoc, Klikdokter and can it be a solution for the development or application of online patient registration and history taking?" In my opinion, everything is now useful in a pandemic like this. Only one thing we might aim at is the source. From the Ministry of Health ${ }^{5}$ instructions and so on. That's all good and it can be accounted for. Only perhaps what we modify is the delivery technique. So we don't have to make up our own or come up with our own terms, making up everything, this can be confusing. In fact, it will be anti-climax later. In my opinion, once again, the information that we have obtained from a government source is good, only a modification of how it is transmitted, how to use a mask,

Do not let herd immunity occur, because once herd immunity arrives, it means that almost half of us are immune because they have been infected. That's why I think it's important that there is only one source, so that information has one source. Almost everything the government has done is evidence based, it has been very good, only maybe sometimes if it is offered to the public, they find it difficult to understand. So we have to change it to a simpler language. So, to make it, there is a need for an understanding and public awareness. Kaya really hopes for primary care doctors because only we are the closest to the community. They believe in us, and whatever we say is likely to be carried out by society.

There are really two primary care doctors, on the one hand we have to deal with patients, on the other hand we have to educate the public. And I am very proud to be a primary care doctor in primary care. Because we can do a lot for the country of Indonesia, "Physical distancing does not keep doctors away from patients, but keeps diseases away from doctors and patients". So we can say that physical distancing is actually that everyone also has to maintain a distance. It is clear the message from the modeling made that everything that is done without Law Inforcement from the Government is how important social distancing is, the consequences will be big. But with social distancing, with the assumption that people are taught to stay at home, not to receive guests first, not to leave the house to chat with neighbors first, it has greatly reduced the incidence, both infection and death. From an epidemiological perspective, from this big data analyst, we can intervene in the number of social contacts. But we can't yet intervene in the period of infection and the magnitude of transmission, but we can intervene in social contact. It is our culture that has high social contact that we must provide knowledge to the 
community to reduce until this transmission rate decreases.

\section{REFERENCE}

1. WHO (World Health Organization). WHO Coronavirus Disease (Covid-19) Dashboard. Online fromhttps:/www.who.int/emergencies/ diseases/novel-coronavirus-2019. Retrieved 8 April 2020.

2. Liu Y, Gayle AA2,Wilder-Smith A.,Rocklöv J. The reproductive number of Covid-19 is higher compared to SARS coronavirus.J Travel Med.2020 Mar 13; 27 (2). pii: taaa021. doi: 10.1093 / jtm / taaa021.

3. Mossong, J., Hens, N., Jit, M., Beutels, P., Auranen, K., Mikolajczyk, R., \& Heijne, J. Social contacts and mixing patterns relevant to the spread of infectious diseases. PLoS medicine, 5 (3). 2008.

4. Lai S, Ruktanonchai N, Zhou L, Prosper O, Luo W, Floyd J. Effect of non pharmaceutical interventions for containing the Covid-19 outbreak: an observational and modeling study. medRxiv. 2020.

5. Indonesian Ministry of Health Corona Virus Update. Online fromhttps://infemerging.kemkes.go.id/. Retrieved 8 April 2020. 